\title{
Evolutionary drivers of the hump-shaped latitudinal gradient of benthic polychaete species richness along the Southeastern Pacific coast
}

\author{
Rodrigo A Moreno ${ }^{1,2}$, Fabio A Labra ${ }^{1,2}{ }^{2}$, Darko D Cotoras ${ }^{\text {Corresp., } 3}$, Patricio A Camus ${ }^{4,5}$, Dimitri Gutiérrez ${ }^{6}$, Luis \\ Aguirre $^{7}$, Nicolás Rozbaczylo ${ }^{8}$, Elie Poulin ${ }^{9}$, Nelson A Lagos ${ }^{1,2}$, Daniel Zamorano ${ }^{2,10}$, Marcelo M Rivadeneira \\ ${ }^{1}$ Facultad de Ciencias, Universidad Santo Tomás, Santiago, Chile \\ 2 Centro de Investigación e Innovación para el Cambio Climático (CIICC), Universidad Santo Tomás, Santiago, Chile \\ 3 Entomology Department, California Academy of Sciences, San Francisco, California, United States \\ 4 Departamento de Ecología, Facultad de Ciencias, Universidad Católica de la Santísima Concepción, Concepción, Chile \\ 5 Centro de Investigación en Biodiversidad y Ambientes Sustentables (CIBAS), Universidad Católica de la Santísima Concepción, Concepción, Chile \\ 6 Dirección de Investigaciones Oceanográficas y de Cambio Climático, Instituto del Mar del Perú (IMARPE), Callao, Perú \\ 7 Laboratorio de Biología y Sistemática de Invertebrados Marinos (LaBSIM), Facultad de Ciencias Biológicas, Universidad Nacional Mayor de San Marcos, \\ Lima, Perú \\ 8 FAUNAMAR Ltda. Consultorías Medio Ambientales e Investigación Marina, Santiago, Chile \\ 9 Instituto Milenio de Ecología y Biodiversidad (IEB), Facultad de Ciencias, Universidad de Chile, Santiago, Chile \\ 10 Department of Zoology, University of Otago, Dunedin, New Zealand \\ 11 Centro de Estudios Avanzados en Zonas Áridas (CEAZA), Universidad Católica del Norte, Coquimbo, Chile \\ 12 Departamento de Biología Marina, Facultad de Ciencias del Mar, Universidad Católica del Norte, Coquimbo, Chile \\ 13 Departamento de Biología, Universidad de La Serena, La Serena, Chile \\ Corresponding Author: Darko D Cotoras \\ Email address: darkocotoras@gmail.com
}

Latitudinal diversity gradients (LDG) and their explanatory factors are among the most challenging topics in macroecology and biogeography. Despite of its apparent generality, a growing body of evidence shows that 'anomalous' LDG (i.e., inverse or hump-shaped trends) are common among marine organisms along the Southeastern Pacific (SEP) coast. Here, we evaluate the shape of the LDG of marine benthic polychaetes and its underlying causes using a dataset of 643 species inhabiting the continental shelf ( $<200 \mathrm{~m}$ depth), using latitudinal bands with a spatial resolution of $0.5^{\circ}$, along the SEP (3-55ㅇ). The explanatory value of six oceanographic (Sea Surface Temperature (SST), SST range, salinity, salinity range, primary productivity and shelf area), and one macroecological proxy (median latitudinal range of species) were assessed using a random forest model. The taxonomic structure was used to estimate the degree of niche conservatism of predictor variables and to estimate latitudinal trends in phylogenetic diversity, based on three indices (phylogenetic richness $\left(\mathrm{PD}_{\mathrm{SES}}\right)$, mean pairwise distance $\left(\mathrm{MPD}_{\mathrm{SES}}\right)$, and variation of pairwise distances (VPD)). The LDG exhibits a hump-shaped trend, with a maximum peak of snecies richness at ca. 4205 declining towards northern and southern areas of
Peerj reviewing PDF $\mid(2020: 05: 48774: 3: 0:$ NEW 24 Jul 2021) 
SEP. The latitudinal pattern was also evident in local samples controlled by sampling effort. The random forest model had a high accuracy (pseudo- $r^{2}=0.95$ ) and showed that the LDG could be explained by four variables (median latitudinal range, SST, salinity, and SST range), yet the functional relationship between species richness and these predictors was variable. A significant degree of phylogenetic conservatism was detected for the median latitudinal range and $\mathrm{SST}_{\mathrm{S}} \mathrm{PD}_{\mathrm{SES}}$ and $\mathrm{MPD}_{\mathrm{SES}}$ increased toward the southern region, whereas VPD showed the opposite trend. Our results reinforce the idea that the south Chile fjord area, particularly the Chiloé region, was likely the evolutionary source of new species of marine polychaetes along SEP, creating a hotspot of diversity. Therefore, in the same way as the canonical LDG shows a decline in diversity while moving away from the tropics; on this case the decline occurs while moving away from Chiloé Island. These results, coupled with a strong phylogenetic signal of the main predictor variables suggest that processes operating mainly at evolutionary timescales govern the LDG. 
1 Evolutionary drivers of the hump-shaped latitudinal gradient of benthic polychaete species

2

3

4

5 Rodrigo A. Moreno ${ }^{1,2}$, Fabio A. Labra ${ }^{1,2}$, Darko D. Cotoras ${ }^{3 *}$, Patricio A. Camus ${ }^{4,5}$, Dimitri

6 Gutiérrez $^{6}$, Luis Aguirre ${ }^{7}$, Nicolás Rozbaczylo ${ }^{8}$, Elie Poulin ${ }^{9}$, Nelson A. Lagos ${ }^{1,2}$, Daniel

7 Zamorano ${ }^{2,10}$ \& Marcelo M. Rivadeneira ${ }^{11,12,13}$

8

$9 \quad{ }^{1}$ Facultad de Ciencias, Universidad Santo Tomás, Santiago, Chile

$10{ }^{2}$ Centro de Investigación e Innovación para el Cambio Climático (CIICC), Universidad Santo

11 Tomás, Santiago, Chile

$12{ }^{3}$ Entomology Department, California Academy of Sciences, San Francisco, California, USA

$13{ }^{4}$ Departamento de Ecología, Facultad de Ciencias, Universidad Católica de la Santísima

14 Concepción, Concepción, Chile

$15{ }^{5}$ Centro de Investigación en Biodiversidad y Ambientes Sustentables (CIBAS), Universidad

16 Católica de la Santísima Concepción, Concepción, Chile

$17{ }^{6}$ Dirección de Investigaciones Oceanográficas y de Cambio Climático, Instituto del Mar del Perú

18 (IMARPE), Callao, Perú

$19{ }^{7}$ Laboratorio de Biología y Sistemática de Invertebrados Marinos (LaBSIM), Facultad de

20 Ciencias Biológicas, Universidad Nacional Mayor de San Marcos, Lima, Perú

$21{ }^{8}$ FAUNAMAR Ltda. Consultorías Medio Ambientales e Investigación Marina, Santiago, Chile

22 Instituto Milenio de Ecología y Biodiversidad (IEB), Facultad de Ciencias, Universidad de

23 Chile, Santiago, Chile

Peer) reviewing PDF | (2020:05:48774:3:0:NEW 24 Jul 2021) 
$24{ }^{10}$ Department of Zoology, University of Otago, Dunedin, New Zealand

$25{ }^{11}$ Centro de Estudios Avanzados en Zonas Áridas (CEAZA), Universidad Católica del Norte,

26 Coquimbo, Chile

$27{ }^{12}$ Departamento de Biología Marina, Facultad de Ciencias del Mar, Universidad Católica del

28 Norte, Coquimbo, Chile

$29{ }^{13}$ Departamento de Biología, Universidad de La Serena, La Serena, Chile

33 *Corresponding author: Darko D. Cotoras E-mail: darkocotoras@gmail.com

34 Mailing address: Department of Entomology, California Academy of Sciences, San Francisco, 35 California, 94118, USA 
Abstract

39 Latitudinal diversity gradients (LDG) and their explanatory factors are among the most challenging topics in macroecology and biogeography. Despite of its apparent generality, a

41 growing body of evidence shows that 'anomalous' LDG (i.e., inverse or hump-shaped trends) are common among marine organisms along the Southeastern Pacific (SEP) coast. Here, we evaluate the shape of the LDG of marine benthic polychaetes and its underlying causes using a dataset of 643 species inhabiting the continental shelf $(\leq 200 \mathrm{~m}$ depth), using latitudinal bands with a spatial resolution of $0.5^{\circ}$, along the SEP $\left(3-55^{\circ} \mathrm{S}\right)$. The explanatory value of six oceanographic 46 (Sea Surface Temperature (SST), SST range, salinity, salinity range, primary productivity and shelf area), and one macroecological proxy (median latitudinal range of species) were assessed using a random forest model. The taxonomic structure was used to estimate the degree of niche conservatism of predictor variables and to estimate latitudinal trends in phylogenetic diversity, based on three indices (phylogenetic richness $\left(\mathrm{PD}_{\mathrm{SES}}\right)$, mean pairwise distance $\left(\mathrm{MPD}_{\mathrm{SES}}\right)$, and variation of pairwise distances (VPD)). The LDG exhibits a hump-shaped trend, with a maximum peak of species richness at ca. $42^{\circ} \mathrm{S}$, declining towards northern and southern areas of SEP. The latitudinal pattern was also evident in local samples controlled by sampling effort. The random forest model had a high accuracy (pseudo- $\left.r^{2}=0.95\right)$ and showed that the LDG could be explained by four variables (median latitudinal range, SST, salinity, and SST range), yet the functional relationship between species richness and these predictors was variable. A significant degree of phylogenetic conservatism was detected for the median latitudinal range and SST.

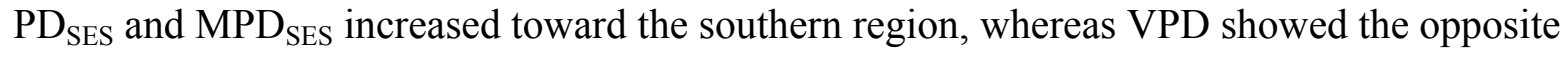
trend. Our results reinforce the idea that the south Chile fjord area, particularly the Chiloé region, was likely the evolutionary source of new species of marine polychaetes along SEP, creating a 
61 hotspot of diversity. Therefore, in the same way as the canonical LDG shows a decline in

62 diversity while moving away from the tropics; on this case the decline occurs while moving

63 away from Chiloé Island. These results, coupled with a strong phylogenetic signal of the main

64 predictor variables suggest that processes operating mainly at evolutionary timescales govern the 65 LDG.

66

67

68

69

\section{Introduction}

Latitudinal diversity gradients (LDG) have been studied for over two centuries and the search for patterns and their processes remain an active topic in biogeography, macroecology and evolution (Pianka 1966; Willig et al. 2003, Hillebrand 2004a, Mittelbach et al. 2007, Tittensor et al. 2010, Kinlock et al. 2018, Pontarp et al. 2019). Several meta-analyses have shown the interhemispheric consistency of a monotonic increase in species richness from high latitudes to the tropics, producing a unimodal (canonical) pattern on a global scale (i.e. Willig et al. 2003, Hillebrand 2004a, b, Costello et al. 2017, Worm \& Tittensor 2018, Kinlock et al. 2018, Menegotto et al. 2018, 2019, Rivadeneira \& Poore 2020). However, there is considerable debate regarding the underlying factors that determine the LDG (Rohde 1992, Willig et al. 2003, Mittelbach et al. 2007, Pontarp et al. 2019).

Synthesis achieved during the last decades recognize that explanations for the canonical LDG (i.e., increasing species richness towards the tropics) can be broadly classified into three major hypotheses categories (Mittelbach et al. 2007, Pontarp et al. 2019): 'ecological limits', 'diversification dynamics' and 'time for species accumulation'. The category of 'ecological limits' refers to explanations based on present-day environmental conditions via higher productivity, carrying capacity, species coexistence, or niche breadth (Currie 1991, Rosenzweig 
84 1995, Evans et al. 2005). The 'diversification dynamics' hypotheses suggest that the LDG are 85 generated by latitudinal variation in diversification rates, with greater speciation and/or lower extinction rates in the tropics (Evans et al. 2005, Weir \& Schluter 2007). The 'time for species

87 accumulation' hypotheses explanations invoke the tropics as sources of evolutionary novelties, where clades originate making the LDG the result of dispersal limitation towards subtropical zones (Wiens \& Donoghue 2004, Wiens \& Graham 2005, Jablonski et al. 2013). continental and marine taxa (see Platnick 1991, Kindlmann et al. 2007; Tittensor, 2010, Worm \& Tittensor, 2018, Kinlock et al. 2018). A growing body of evidence shows that non-canonical LDG (i.e., inverse or hump-shaped trends) are common among marine organisms at a global scale (Chaudhary et al. 2016, Wooley et al. 2016, Rivadeneira \& Poore 2020). This same phenomenon has been reported along the Southeastern Pacific coast $\left(0-56^{\circ} \mathrm{S}\right.$, hereafter SEP) and also involve widely different taxa such as macroalgae (Santelices 1982, Santelices \& Marquet 1998, Santelices et al. 2009), sponges (Desqueyroux \& Moyano 1987), anthozoans (Häussermann \& Försterra 2005), bryozoans (Moyano 1991), polyplacophorans (Navarrete et al. 2020), gastropod and bivalves (Herm 1969, Valdovinos et al. 2003), polychaetes (Lancellotti \& Vásquez 2000, Hernández et al. 2005, Moreno et al. 2006) and different groups of crustaceans

101 (Fernández et al. 2009, Rivadeneira et al. 2011). These inverse trends along the SEP have been 102 shown to not be the result of sampling artifacts (see Valdovinos et al. 2003, Rivadeneira et al. 103 2011). received little attention and available studies have been mainly descriptive (see Lancellotti \& 106 Vásquez 1999, 2000). Indeed, a significant gap in knowledge in the whole Eastern Pacific and 
107 Chile in particular, is recognized on a recent global study of polychaete biogeography

108 (Pamungkas et al. 2021). However, Hernández et al. (2005) and Moreno et al. (2006) evaluated

109 the latitudinal change in species richness of benthic polychaetes along the coast of Chile

110 (between Arica at $18^{\circ} \mathrm{S}$ and Cape Horn at $56^{\circ} \mathrm{S}$ ), finding a hump-shaped LDG with a maximum

111 peak around Chiloé Island (ca. $\left.41-42^{\circ} \mathrm{S}\right)$ in southern Chile. These authors proposed that this

112 pattern might be determined by geometric constraints and historical events such as eustatic

113 movements, cyclic effects of El Niño-Southern Oscillation, shallowing of the oxygen minimum

114 zone and glacial advances and retreats, all of which have mainly occurred since the Neogene

115 (i.e., during the last 23 Mya). Although these studies represented a significant advance in

116 understanding the mechanisms that may generate the hump-shaped LDG, their analyses used a

117 low spatial resolution ( $3^{\circ}$ latitude bands) to register species occurrences and constrained the

118 study area to the geopolitical limits of Chile (an arbitrary decision shared by the majority of

119 studies in other taxa. i.e., Desqueyroux \& Moyano 1987, Moyano 1991, Fernández et al. 2009,

120 Rivadeneira et al. 2011, Lee \& Riveros 2012). In these studies (Hernández et al. 2005, Moreno

121 et al. 2006), therefore, the exclusion of a vast portion of the Warm Temperate Southeastern

122 Pacific biogeographic province (sensu Spalding et al. 2007) could generate spurious results

123 derived from truncating the real biogeographic limits of these polychaete species.

$124 \quad$ Here, we reappraise the patterns and processes related to the LDG reported for benthic

125 polychaetes in Chile, using a greater spatial extent $\left(3-56^{\circ} \mathrm{S}\right)$ and resolution $\left(0.5^{\circ}\right.$ latitude $)$ than

126 prior analyses. The northern end is defined by the Guayaquil Gulf (limit between the

127 Panamanian and Peruvian-Chilean Provinces, Vegas-Velez 1980, Boschi 2000, Robertson \&

128 Cramer 2009, Ibanez-Erquiaga et al. 2018), while the southern limit consist in the end of the

129 South American continent isolated from Antarctica by the Circumpolar Current. Regarding the 
130 southern limit, differences in polychaete community composition have been already reported

131 between the Magellan region and Weddell Sea shelves (Montiel et al. 2005).

132 The existence of non-canonical LDG along the SEP could be the result of a complex

133 interaction of several factors, instead of a single dominant one. To give explanation to multi-

134 variate and non-linear phenomena a statistical framework which incorporates and differentially

135 weights each factor is required. Our approach would be to simultaneously evaluate the relative

136 contribution of several proxies (SST, salinity, shelf area, etc.) which have been previously

137 associated with specific hypothesis to explain LDG, using machine learning methods. The

138 explanatory hypotheses considered can be separated into three categories: 'ecological limits',

139 'diversification dynamics', and 'time for species accumulation' (Table 1). These categories have

140 been adapted from the conceptual framework used to study the canonical LDG (Mittelbach et al.

141 2007, Pontarp et al. 2019).

142 Regarding 'ecological limits', we will consider three hypotheses: (1) Seasonal

143 coexistence (Valentine \& Jablonski 2015), which predicts that diversity will decline in areas with

144 abiotic seasonal changes (Diversity 1/œ SST range and Salinity range); (2) Species-area effect

145 (Chown et al. 2000, Valdovinos et al. 2003), which predicts that diversity will be a direct

146 function of the available area (Diversity $\propto$ Shelf area); and (3) Energy-dependency (Hawkins et

147 al. 2003, Evans et al. 2005), which predicts that diversity will increase with more energy

148 available in the ecosystem (Diversity $\propto$ Primary Productivity). In the category of 'diversification

149 dynamics', we will consider two hypotheses: (1) Long term climate stability (Dynesius \&

150 Jansson 2000), which predicts that more stable areas will accumulate more species (Diversity

$1511 / \propto$ Median latitudinal range of the species) and (2) Temperature-dependent speciation (Rohde

152 1992, Allen et al. 2006), which predicts a positive association between speciation rates and 
153 ambient temperature (Diversity $\propto$ SST). Finally, in the category of 'time for species

154 accumulation', we will assess one hypothesis about Niche conservatism (Wiens \& Donoghue

155 2004), which predicts that species will tend to retain preferences for the ecological conditions

156 where they originally evolved (Diversity $\propto$ constancy in SST, salinity, SST range, Median

157 latitudinal range of the species, and Salinity range). As all these explanatory variables may

158 reflect processes operating at both ecological and evolutionary timescales, we have selected them

159 as candidate variables to build a machine learning model to explain the polychaete LDG in the

160 SEP.

161 In addition, the study of phylogenetic diversity may shed light into the role of

162 evolutionary processes shaping patterns of species richness (Davies \& Buckley 2011, Fritz \&

163 Rahbek 2012, Eme et al. 2020). For instance, a species-rich area composed by many closely

164 related species (i.e., low phylogenetic diversity) may imply elevated in situ speciation rates of

165 some lineages. On the contrary, a species-rich area composed by many distantly related species

166 (i.e., high phylogenetic diversity) may be associated to immigration influenced by filtering effect

167 acting upon a trait phylogenetically over dispersed. There are many $\alpha$-phylogenetic diversity

168 indices (Winter et al. 2013), that can be broadly classified into three categories that measures

169 amount of richness, divergence and regularity (Tucker et al. 2017); therefore, the combined used

170 of indices reflecting each one of these three aspects may be more informative of the role of

171 evolutionary processes shaping species richness (Davies \& Buckley 2011, Fritz \& Rahbek 2012,

172 Eme et al. 2020). Despite the fact that these phylogenetic diversity indices are typically based on

173 calibrated molecular phylogenies, the taxonomic structure may be still be used as a coarse proxy

174 of phylogenetic relationships of species in groups lacking robust and complete molecular

175 phylogenies (Soul \& Friedman et al. 2015). In fact, multiple studies in marine taxa have 
176 analyzed latitudinal trends in phylogenetic diversity using this taxonomic approach (Woodd-

177 Walker et al. 2002, Ellingsen et al. 2005, Tolimieri \& Anderson 2010, Rivadeneira et al. 2011,

178 Azovsky et al. 2016, Wu et al. 2016). This opens the possibility to explore latitudinal patterns of

179 phylogenetic diversity in benthic polychaetes along SEP and its connection with the LDG

180 phenomenon.

181 Our study area encompasses a broad latitudinal gradient of oceanographic conditions

182 spanning more than 50 degrees of latitude, from tropics to sub-polar areas, and hence it is ideal

183 to study the role of 'ecological limits' on the LDG (Astorga et al. 2003, Valdovinos et al. 2003,

184 Fernández et al. 2009). At the same time the marine biota at SEP experienced a drastic turnover

185 during the late Cenozoic, driven by tectonic, physiographic, climatic, and oceanographic shifts

186 (Herm 1969, Rivadeneira \& Marquet 2007, Kiel \& Nielsen 2010, Villafaña \& Rivadeneira 2014,

187 Rivadeneira \& Nielsen 2017). These alterations induced latitudinal differences in the

188 diversification trends that created the inverse LDG characterizing present-day bivalves and

189 gastropods along the SEP (Kiel \& Nielsen 2010) and may have also driven the LDG of benthic

190 polychaetes (Moreno et al. 2006). Thus, SEP is also an ideal region to study the role of

191 evolutionary and historical processes (i.e., 'diversification dynamics', and 'time for species

192 accumulation') shaping the LDG. Therefore, the specific goals of our study are: (1) to re-

193 evaluate the existence of a hump-shaped LDG, including the entire Peruvian and Magellanic

194 biogeographic provinces along the SEP, and (2) to jointly evaluate different hypotheses (by

195 significance assessment of proxies), which could explain the formation of a hump-shaped LDG.

196 Our study confirms the existence of a non-canonical LDG, robust to sampling bias, and suggests

197 that the underlying explanations may be linked to processes occurring at evolutionary timescales. 198 


\section{Materials and methods}

200 Database

201 This study relies on a database which: (a) includes 643 polychaete species found between $3^{\circ} \mathrm{S}$

202 (southern Ecuador) and 56 ${ }^{\circ} \mathrm{S}$ (Cape Horn, Chile) inhabiting the continental shelf (i.e., $\leq 200 \mathrm{~m}$

203 depth) (Fig. 1A), (b) summarizes information compiled from exhaustive reviews of literature (ca.

2041,000 bibliographic references), museum collections and field expeditions, integrating more than

205160 years of studies over the SEP, (c) was constructed using georeferenced data from geographic

206 information systems (Datum WGS84), (d) was enriched by intensive field samplings conducted

207 over the last decade for updating records and correcting biogeographical biases, particularly in

208 southern Chile where diversity surveys historically had been scarce, specially through the

209 research cruises CIMAR Fiordos 13, 14, 15, 17 and 18, and (e) was complemented with existing

210 records from the OBIS database (OBIS 2021). Taxonomy was cross-validated with the World

211 Register of Marine Species (WoRMS Editorial Board, 2021). Altogether, such information

212 currently constitutes the most complete database of benthic polychaetes in this region of the

213 world. The reported latitudinal ranges of all species used in this study are provided in the Dataset

214 S1 in the Supporting information.

215 We first determined the maximum and minimum latitude of geographic distribution of

216 each species and assigned species presence into $0.5^{\circ}$ latitudinal bands using a range-through

217 approach (i.e., assuming a continuous geographic distribution between their range limits), as

218 commonly done in marine macroecological studies (Roy et al. 1998, Tomašových et al. 2016).

219 OBIS records were used to estimate the latitudinal limits of species beyond our study area along

220 the eastern Pacific, from Antarctica to Alaska. We also examined whether differences in the

221 sampling intensity may potentially mask the overall pattern, that is to say, whether areas of 
222 higher species richness may be the result of higher sampling effort. In order to test this potential

223 confounding factor, we used 57 soft-bottom benthic assemblages sampled in the coastal shelf and

224 collated from a literature survey. Since the sampling effort was not the same (i.e. different

225 sampling devices and number of samples) we used the number of individuals reported for each

226 species and each site to carry out a rarefaction analysis. This method estimates the expected

227 species richness for a similar number of individuals sampled (Sanders 1968, Gotelli \& Colwell

228 2001). In our case, we set $E_{s}=20$ (the site with a smaller number of individuals). The information

229 containing the local occurrences and abundances of 152 species in the 57 local assemblages is

230 presented in the Dataset S2. We estimated the mean rarefied species richness per $0.5^{\circ}$ latitudinal

231 bin and correlated it with the species richness estimated with the range-though approach. In the

232 absence of severe spatial bias in sampling intensity, the correlation between rarefied and

233 regional-scale species richness should be positive and significant. However, patterns of species

234 richness may not be necessarily similar across spatial scales (Gray 2002; Rivadeneira et al. 2002,

235 Hillebrandt 2004a,b, Edgar et al. 2017), and in fact the relationship between local and regional

236 species richness may be non-linear, i.e. at higher regional species richness local assemblages

237 may be saturated (Ricklefs 1987, Srivastava 1999, Rivadeneira et al. 2002). The contrary trend,

238 i.e. a linear relationship between local and regional species richness, suggests that local

239 assemblages may be 'open' to the dispersal of species from the regional pool (Ricklefs 1987).

240 We explored this idea by carrying out a second-order polynomial OLS regression, where the

241 significance of the terms can be used to support the saturation (i.e., significant quadratic

242 component) or unsaturation (significant linear component, but non-significant quadratic term) of

243 local assemblages. 


\section{Hypothesis testing}

246 We evaluated the importance of six oceanographic variables (Sea Surface temperature (SST),

247 SST range, salinity, salinity range, primary productivity and shelf area), which were used as

248 proxies for three hypothesis categories currently used to explain canonic LDG (Mittelbach et al.

249 2007, Pontarp et al. 2019, Table 1). They were obtained from the Bio-Oracle Database v.2.0

250 (Assis et al. 2018) and GMED database (http://gmed.auckland.ac.nz) (information provided in

251 the Dataset S3). Values were averaged over half-degree latitudinal bins, using only pixels on the

252 coastal shelf $(<200 \mathrm{~m}$ depth). The entire dataset of environmental predictors is available in the

253 Dataset S3. In addition, we used the median latitudinal range of all species contained at each

254 latitudinal bin as a coarse proxy of the 'long-term climatic stability hypothesis'. Since many

255 species have latitudinal ranges spanning beyond the study area, we used the actual latitudinal

256 ranges estimated for the entire eastern Pacific coast (from Antarctica to Alaska).

257 The role of all predictors shaping the LDG was evaluated using a random forest

258 approach. Random forest, a machine learning method, offers multiple advantages over traditional

259 GLM/GLS methods commonly used on previous studies (Kreft \& Jetz, 2007, Tittensor et al.

260 2010): no error structure is assumed, it deals with classification and regression problems, it can

261 handle a large number of predictors, and is robust to overfitting (Breiman 2001, Liaw \& Wiener

262 2002). We used standard tuning hyperparameters, setting mtry $=p / 3$ (where $p$ is the number of

263 predictors per tree), and node size $=5$. Variable importance was estimated using a conditional

264 random forest which accounts for the possible predictor collinearity (Strobl et al. 2008), based on

265 the method proposed by Altmann et al. (2010), with p-values based on 10,000 permutations, and

266 implemented in the library ranger (Wright \& Zielger, 2014) in R. Nevertheless, the degree of

267 predictor multicollinearity, measured as the variance inflation factor (Dormann et al. 2013, 
268 Naimi et al. 2014), was below the threshold of 10 commonly used in the literature (Table 2).

269 Partial dependence plots were used to inspect the conditional shape of the predicted species

270 richness versus selected predictors, using the library pdp (Greenwell, 2017) in R. A partial

271 dependence plot allows us to visualize the functional relationship between the species richness

272 and the predictor variables isolated from the effect of other predictors. The existence of spatial

273 autocorrelation in the residuals of the model, another potential bias on the identification of

274 variable importance (Diniz-Filho et al. 2003), was evaluated using a spatial autocorrelogram

275 analysis (i.e., Moran's I versus geographic distance) with 1,000 runs in the library ncf in R

276 (Bjornstad, 2019).

277 Although some of the environmental predictors (e.g., SST) may be considered as a proxy

278 for evolutionary hypotheses, we also evaluated the importance of evolutionary processes on the

279 LDG using two additional approaches. We used taxonomy as a coarse proxy of the phylogenetic

280 relationships (Soul \& Friedman 2015), since we lack a full and well-resolved phylogeny for our

281 species. First, we estimated three indices of $\alpha$-phylogenetic diversity that summarizes different

282 facets of the evolutionary relatedness of species, namely phylogenetic richness (Faith's PD),

283 divergence (mean pairwise distance, MPD), and regularity (variation of pairwise distances, VPD)

284 (Tucker et al. 2017). PD measures the total distance from each tip to the root of the tree, and it is

285 used as a proxy of the total evolutionary history summed by all species in a given region (Faith

286 1992, Winter et al. 2013). The MPD (also known as AvTD, and $\Delta^{+}$, Clarke \& Warwick 1998)

287 measures the mean phylogenetic distance (i.e., branch length) among all pairs of species within a

288 given latitudinal bin. We estimated their standardized effect sizes (SES = [observed- mean

289 simulated] / SD simulated) of PD and MPD in order to account for their dependence on species

290 richness, by randomizing the original species matrix 1,000 times. SES values lower than 
291 expected by the null model suggest phylogenetic clustering, whereas values higher than expected

292 indicate phylogenetic overdispersion/convergence. We also estimated the VPD (Warwick \&

293 Clarke, 2001) as a measure of the regularity of the phylogenetic distances among all species in

294 each latitudinal bin. Analyses were carried out using the libraries vegan (Oksanen et al. 2019)

295 and picante (Kembel et al. 2010) in R.

296 As a second approach to estimate the importance of evolutionary processes shaping the

297 LDG, we determined the phylogenetic signal of each proxy, using Blomberg's K (Blomberg et

298 al. 2003) in order to test the importance of the Niche conservatism hypothesis (within the 'time

299 for species accumulation' category). This was carried out using the median value of each proxy

300 estimated across the entire latitudinal distribution. Larger values of $\mathrm{K}$ indicate a strong

301 phylogenetic conservatism of the proxy. Analyses were carried out using the libraries ape

302 (Paradis et al. 2004), paleotree (Bapst 2012), and picante (Kembel et al. 2010) in R. The script

303 used to run all analyses and to create each figure is provided in the supplementary material

304 (Scripts S4).

305

306 Results

307 Our compiled data set shows that the species diversity of benthic polychaetes along the SEP

308 presents a hump-shaped LDG (Fig. 1B). The maximum richness ( 299 species) occurs at $42^{\circ} \mathrm{S}$,

309 which is 2 -fold higher than in southern Ecuador $\left(3^{\circ} \mathrm{S}\right)$ where richness was 152 species. A

310 secondary peak is located ca. $53^{\circ} \mathrm{S}$, and then species richness drops abruptly towards $55^{\circ} \mathrm{S}$, with

311 species richness levels similar to those observed in Perú and southern Ecuador. The evaluation of

312 potential sampling artifacts showed that rarefied species richness in local assemblages has the

313 same trend observed when using the range-through approach $(\mathrm{r}=0.49, \mathrm{p}=0.009, \mathrm{n}=29$ bins, 
314 Fig. 1B), and no evidence of saturation was detected, as the linear but not the quadratic term of

315 the local vs. regional OLS regression was significant ( $\mathrm{p}=0.008$ and 0.179 , respectively).

316 The random forest model showed a high accuracy predicting the LDG (Figs. 2A and 3A),

317 with a pseudo- $\mathrm{r}^{2}=0.95$. The model underestimated the species richness in the most extreme

318 latitudinal bins (Fig. 2B), but overall spatial autocorrelation was not detected at any spatial

319 distance (Fig. 2C). Out of the seven predictors, four were significant (median latitudinal range,

320 SST, salinity and SST range; ranked according to its importance, see Table 2). For a reference of

321 the latitudinal variation of the selected variables see Fig. 3B-C. Partial dependence shows a

322 hump-shaped response of species richness to SST (Fig. 4A), with maximum values at ca. $12^{\circ} \mathrm{C}$.

323 A more pronounced hump-shaped response of species richness was observed for SST range (Fig.

324 4B). Salinity and median latitudinal range showed a monotonic negative relationship with

325 species richness, which reaches maximum values at the lowest salinity levels (Fig. 4C) and bins

326 with lower median latitudinal ranges (Fig. 4D).

327 The three phylogenetic diversity indices showed different latitudinal trends and their

328 correlation to species richness varied in sign and magnitude (Fig. 5). While $\mathrm{PD}_{\mathrm{SES}}$ was positively

329 correlated to species richness $\left(\mathrm{r}_{\text {Pearson }}=0.51, \mathrm{p}<0.0001\right.$, Fig. $\left.5 \mathrm{~A}\right), \mathrm{MPD}_{\mathrm{SES}}$ did not show a

330 significant relationship $\left(\mathrm{r}_{\text {Pearson }}=0.04, \mathrm{p}=0.69\right.$, Fig. $\left.5 \mathrm{~B}\right)$, and VPD was negatively correlated

331 with species richness ( $\mathrm{r}_{\text {Pearson }}=-0.49 \mathrm{p}<0.0001$, Fig. 5C). $\mathrm{PD}_{\mathrm{SES}}$ values were not different than

332 expected by the null models for most of the latitudinal gradient (Fig. 5A, B), except by areas

333 around the north Chile and Perú (north of $20^{\circ} \mathrm{S}$ ). Observed $\mathrm{MDP}_{\mathrm{SES}}$ values were significantly

334 lower than expected in two large areas centered around Chiloé $\left(41^{\circ} \mathrm{S}\right)$, and northern Chile and

335 Perú $\left(\right.$ ca. $\left.15^{\circ} \mathrm{S}\right)$. For both $\mathrm{PD}_{\mathrm{SES}}$ and $\mathrm{MDP}_{\mathrm{SES}}$ these negative values suggested a phylogenetic 
336 clustering pattern. Blomberg's K was only significant for the median latitudinal range, SST and

337 primary productivity (Table 2 ).

338

339 Discussion

340 Our study supports the existence of a hump-shaped LDG for benthic polychaetes along the SEP,

341 increasing the number of exceptions to the canonical pattern of higher species richness towards

342 the tropics, both in the SEP and other regions (i.e., Moyano 1991, Valdovinos et al. 2003, Willig

343 et al. 2003, Hillebrand 2004a, b, Kindlmann et al. 2007, Santelices et al. 2009, Rivadeneira et al.

344 2011). Particularly, it is congruent with a recently published global study on latitudinal gradients

345 of polychaetes (Pamungkas et al. 2021). Our research also confirms previous results for benthic

346 polychaetes along SEP (Hernández et al. 2005, Moreno et al. 2006) based on partial datasets of a

347 more restricted scale and lower spatial resolution ( $c a ., 3^{\circ}$ of latitude), and it seems robust to

348 possible sampling artifacts, as the overall shape of the LDG still holds after accounting for

349 differences in sampling in local assemblages. Therefore, the recorded pattern in this study

350 reflects a robust biogeographic pattern for benthic polychaetes in the SEP.

351 Our analyses reveal that the LDG of polychaete species is well explained by a reduced

352 subset of predictors that could be attributed to processes operating mainly, but not exclusively, at

353 evolutionary timescales (Table 1). Overall, these significant variables (median latitudinal range,

354 SST, salinity, and SST range) are proxies for the predictions of four (Long term climate stability,

355 Niche conservatism, Temperature-dependent speciation, and Seasonal coexistence) of the six

356 'specific hypothesis', corresponding to all three hypotheses categories proposed in previous

357 literature (Mittelbach et al. 2007, Pontarp et al. 2019). It is important to note that all the selected

358 predictors are also linked to 'time for species accumulation' category, and particularly to the 
359 hypothesis of 'niche conservatism' (Wiens \& Donoghue 2004). This hypothesis is independently

360 supported by the detection of significant phylogenetic signal (Blomberg's K) in the two most

361 important predictors (median latitudinal range and SST). In addition, the LDG is also correlated

362 to spatial patterns of phylogenetic diversity, measured according to three different indices

$363\left(\mathrm{PD}_{\mathrm{SES}}, \mathrm{MPD}_{\mathrm{SES}}\right.$ and VPD).

364

In the context of a non-canonical LDG, as our case, the 'niche conservatism' hypothesis

365

366

367

368

369

370

371

372

373

374

375

376

377

378

379

380

381

assumes that clades are originated outside of the tropics. Although we lack paleontological or

phylogenetic information to fully test this idea, the prevalence of the median latitudinal range as

the most important predictor of the species richness, being also the predictor with a high degree

of phylogenetic conservatism, strongly supports the idea of an extra-tropical origin for many

polychaetes species along the SEP. Areas of high species richness are associated to latitudinal

bins with species with narrower latitudinal ranges, as predicted by the 'Rapoport's rule' (Stevens

1989, Hernández et al. 2005). Our results reinforce the idea that the Southern Chile fjord area,

particularly the Chiloe region, may act as a source of new species of marine polychaetes along

SEP creating a hotspot of diversity (Moreno et al. 2006).

A possible historical explanation for the origin of this hotspot is related with the fact that

during the Last Glacial Maximum (LGM) the Patagonian Ice Sheet covered a large portion of the fjords probably pushing many species from the canals into the glacial coastal line (Davies et al. 2020). Indeed, it has been shown that the populations of the southern bull-kelp (Durvillaea antarctica) on the fjord area correspond to recent, probably post glacial, re-colonization (Fraser et al. 2010), implying the unavailability of this region during the LGM. Chiloé Island corresponds to the northern most coastal area where the ice sheet reached sea level, indeed the north-west part of the island has remained ice-free since the last 35,000 years (Davies et al.

Peerj reviewing PDF | (2020:05:48774:3:0:NEW 24 Jul 2021) 
382 2020). Therefore, the waters around Chiloé Island, especially in the north-west corner, might

383 have worked as marine coastal refugia preserving species with previous more extended

384 distributions towards the south.

385 In addition, the relationship between the LDG and phylogenetic diversity indices also

386 suggest the importance of local diversification processes (i.e., origination and extinction, Davies

387 \& Buckley 2011, Fritz \& Rahbek 2012, Eme et al. 2020). Thus, the significant phylogenetic

388 clustering found in the fjords area (i.e., many species are phylogenetically closely related)

389 suggests that this area may have not only acted as a potential glacial refugia, but also a hotspot of

390 in situ diversification, as seen in the fossil record of marine mollusks of the region (Kiel \&

391 Nielsen 2010).

392 Oceanographically, bidirectional dispersion from this area could be facilitated because

393 precisely at this latitude the West Wind Drift diverges into the Humboldt and Cape Horn

394 currents; running north and south, respectively (Strub et al. 2019). Biologically, the extent of the

395 dispersion might be limited due to the strong niche conservatism detected on latitudinal range

396 and median SST experienced for the species. Additionally, the West Wind Drift might work as a

397 colonization pathway of the SEP from the western Pacific. Altogether, in the same way as the

398 canonical LDG shows a decline in diversity while moving away from the tropics; on this case the

399 decline occurs while moving away from Chiloé Island.

400 On another hand, the existence of phylogenetic clustering in areas of low species richness

401 such as northern Chile and Perú is more consistent with a negative net diversification trend,

402 produced by high extinction rates coupled to species sorting (via selective survival).

403 Paleontological studies have shown the existence of high extinction rates of marine forms during

404 the late Neogene-Pleistocene along the Peruvian and northern Chile coast (Herm 1969, Kiel \& 
405 Nielsen 2010), which are linked to the Neogene onset of the modern Humboldt Current (Dekens 406 et al. 2007). In particular, extinction rates of bivalves and marine vertebrates at that time were

407 phylogenetically clustered (Rivadeneira \& Marquet 2007, Villafaña \& Rivadeneira 2014), likely 408 associated to a strong environmental filtering (e.g., thermal tolerance). If similar processes 409 affected polychaetes at SEP, a high extinction rate with higher survivorship of particular clades 410 via environmental filtering process, they may lead to the impoverished richness and highly 411 clustered phylogenetic richness characterizing the northern Chile and Perú regions.

412 Despite the prevalence of evolutionary-based explanations for the LDG of polychaetes,

413 the lack of phylogenetic signal of the SST range and salinity suggest that processes operating at 414 ecological timescales (i.e., 'ecological limitations') may be also important. In fact SST range is 415 much higher in vast areas of Perú and northern Chile, likely related to the effect of 'El Niño' 416 events, which governs the inter-annual variability of the sea water temperature (Shaffer et al.

417 1999). Associated with this and congruent with the selection of SST as a predictor of our model, 418 a recent study also refers to SST as an important factor to globally shape the polychaetes LDG 419 (Pamungkas et al. 2021).

\section{Conclusions}

422 The SEP provides a natural laboratory for marine biogeography studies given the high 423 diversity of shapes of the LDG in marine taxa. In addition to the existence of canonical LDG 424 (Ojeda et al. 2000, Astorga et al. 2003) and inverse LDG (Santelices \& Marquet 1998, 425 Fernández et al. 2009, Rivadeneira et al. 2011), our results validate the existence of a hump426 shaped LDG in marine benthic polychaetes centered ca. Chiloé Island $\left(41-42^{\circ} \mathrm{S}\right)$. More 427 importantly, the same conceptual framework used to study the canonical LDG phenomenon 
428 could also be used to investigate non-canonical LDGs. The latitudinal patterns of distribution of

429 benthic polychaetes needs to be evaluated in other geographical areas, e.g. central and

430 northeastern Pacific coast, in order to fully understand the generality of the non-canonical LDG,

431 and whether the underlying processes are the same in other regions. In the absence of suitable

432 fossil record for polychaetes, molecular phylogenies of selected clades may shed more direct

433 evidence of the importance of evolutionary processes shaping the LDG in this group. Future

434 studies may be also evaluating the role of dispersal of taxa from other areas of the southern

435 ocean (e.g., Glasby \& Alvarez 1999, Glasby 2005) shaping the 'Chiloé hotspot'. An integration

436 of functional traits of species, and phylogenetic and phylogeographic analysis may help to test

437 and validate the importance of ecological and evolutionary determinants of the diversity of

438 benthic polychaetes.

440 Acknowledgements

441 We thank Luis Quipúzcoa, Edgardo Enríquez and Robert Marquina from the Laboratorio de

442 Bentos Marino of the Instituto del Mar del Perú (IMARPE) for logistical help given to the first

443 author in order to consolidate the construction of the benthic polychaetes database from the coast

444 of Perú. The authors dedicate this work to the memory of Prof. Hugo I. Moyano, a Chilean

445 pioneer marine biogeographer and bryozoologist.

\section{$447 \quad$ Literature cited}


449 Allen PA, Gillooly JF, Savage VM \& Brown JH. 2006. Kinetic effects of temperature on rates

450 of genetic divergence and speciation. Proceedings of the National Academy of Sciences

451 of the United States of America 103: 9130-9135.

452 Altmann,A, Toloşi L, Sander O \& Lengauer T. 2010. Permutation importance: a corrected 453 feature importance measure. Bioinformatics 26(10): 1340-1347.

454 Assis J, Tyberghein L, Bosch S, Verbruggen H, Serrão EA \& De Clerck O. 2018.

455 Bio-ORACLE v2. 0: Extending marine data layers for bioclimatic modelling. Global

$456 \quad$ Ecology and Biogeography 27: 277-284.

457 Astorga A, M Fernández, EE Boschi \& N Lagos. 2003. Two oceans, two taxa and one mode

458 of development: latitudinal diversity patterns of South American crabs and test for

459 possible causal processes. Ecology Letters 6: 420-427.

460 Azovsky A, Garlitska L \& Chertoprud E. 2016. Multi-scale taxonomic diversity of marine

461 harpacticoids: Does it differ at high and low latitudes?. Marine Biology 163: 94.

462 Bapst DW. 2012. paleotree: an R package for paleontological and phylogenetic analyses of

463 evolution. Methods in Ecology and Evolution 3: 803-807.

464 Bjornstad ON. 2019. ncf: Spatial Covariance Functions. R package version 1.2-8.

465 https://CRAN.R-project.org/package $=$ ncf.

466 Blomberg SP, Garland T \& Ives AR. 2003. Testing for phylogenetic signal in comparative

467 data: Behavioral traits are more labile. Evolution 57: 717-745.

468 Boschi EE. 2000. Biodiversity of marine decapod brachyurans of the Americas. Journal of $469 \quad$ Crustacean Biology 20: 337-342.

470 Breiman L. 2001. Random forests. Machine Learning 45: 5-32. 
471 Castiglione S, Mondanaro A, Melchionna M, Serio C, Di Febbraro M, Carotenuto F \&

472 Raia P. 2017. Diversification rates and the evolution of species range size frequency 473 distribution. Frontiers in Ecology and Evolution 5: 147.

474 Chaudhary C, Saeedi H \& Costello MJ. 2016. Bimodality of latitudinal gradients in marine 475 species richness. Trends in Ecology \& Evolution 31: 670-676.

Chown SL \& Gaston KJ. 2000. Areas, cradles and museums: the latitudinal gradient in species richness. Trends in Ecology \& Evolution 15: 311-315.

Clarke KR \& RM Warwick. 1998. A taxonomic distinctness index and its statistical properties. Journal of Applied Ecology 35: 523-531.

Costello MJ \& Chaudhary C. 2017. Marine biodiversity, biogeography, deep-sea gradients, and conservation. Current Biology 27: 511-527.

Currie DJ. 1991. Energy and large-scale patterns of animal- and plant-species richness. The American Naturalist 137: 27-49.

Davies TJ \& Buckley LB. 2011. Phylogenetic diversity as a window into the evolutionary and biogeographic histories of present-day richness gradients for mammals. Philosophical Transactions of the Royal Society B: Biological Sciences 366(1576): 2414-25.

Davies JN, Darvill CM, Lovell H, Bendle JM, Dowdeswell JA, Fabel D, García J, Geiger A, Glasser NF, Gheorghiu DM, Harrison S, Hein AS, Kaplan MR, Martin JRV, Mendelova M, Palmer A, Pelto A, Rodés Á, Sagredo EA, Smedley RK, Smellie JL, Thorndycraft VR. 2020. The evolution of the Patagonian Ice Sheet from $35 \mathrm{ka}$ to the present day (PATICE). Earth-Science Reviews 204: 103152. warm period. Paleoceanography 22: PA3211. 
494 Desqueyroux R \& G Moyano. 1987. Zoogeografía de demospongias chilenas. Boletín de la 495 Sociedad de Biología de Concepción, Chile 58: 39-66.

496 Diniz-Filho JAF, Bini LM \& Hawkins BA. 2003. Spatial autocorrelation and red herrings in geographical ecology. Global Ecology and Biogeography 12: 53-64.

498

499

500

501

502

503

504

505

506

507

508

509

510

511

512

513

514

515

516

Dynesius M \& Jansson R. 2000. Evolutionary consequences of changes in species' geographical distributions driven by Milankovitch climate oscillations. Proceedings of the National Academy of Sciences of the United States of America 97: 9115-9120.

Edgar GJ, Alexander TJ, Lefcheck JS, Bates AE, Kininmonth SJ, Thomson RJ, Duffy JE, Costello MJ, Stuart-Smith RD. 2017. Abundance and local-scale processes contribute to multi-phyla gradients in global marine diversity. Science advances 3: e1700419.

Ellingsen KE, Clarke KR, Somerfield PJ \& Warwick RM. 2005. Taxonomic distinctness as a measure of diversity applied over a large scale: the benthos of the Norwegian continental shelf. Journal of Animal Ecology 74: 1069-1079.

Eme D, Anderson MJ, Myers EM, Roberts CD \& Liggins L. 2020. Phylogenetic measures reveal eco-evolutionary drivers of biodiversity along a depth gradient. Ecography 43: 689-702.

Evans KL, PH Warren \& KJ Gaston. 2005. Species-energy relationships at the macroecological scale: a review of the mechanisms. Biological Reviews 80: 1-25.

Faith DP. 1992. Conservation evaluation and phylogenetic diversity. Biological Conservation 61: $1-10$. 
517 Fernández M, Astorga A, Navarrete SA, Valdovinos C \& Marquet PA. 2009.

518 Deconstructing latitudinal species richness patterns in the ocean: does larval development

519 hold the clue?. Ecology Letters 12: 601-611.

520 Fraser CI, Thiel M, Spencer HG \& Waters JM. 2010. Contemporary habitat discontinuity and 521 historic glacial ice drive genetic divergence in Chilean kelp. BMC Evolutionary Biology 10: 203.

Fritz SA \& Rahbek C. 2012. Global patterns of amphibian phylogenetic diversity. Journal of Biogeography 39(8): 1373-1382.

525 Glasby CJ \& Alvarez B. 1999. Distribution patterns and biogeographic analysis of Austral Polychaeta (Annelida). Journal of Biogeography 26(3): 507-533.

527

528

530

531

532

533

534

535

536

537

538 Ecology 26(3-4): 235-245.

Gotelli NJ \& Colwell RK. 2001. Quantifying biodiversity: procedures and pitfalls in the measurement and comparison of species richness. Ecology Letters 4: 379-391.

Gray JS. 2002. Species richness of marine soft sediments. Marine Ecology Progress Series 244: 285-297.

Greenwell BM. 2017. pdp: an R Package for constructing partial dependence plots. The R journal 9: 421-436.

Häussermann V \& G Försterra. 2005. Distribution patterns of Chilean shallow-water sea anemones (Cnidaria: Anthozoa: Actiniaria, Corallimorpharia); with a discussion of the taxonomic and zoogeographic relationships between the actinofauna of the South East Pacific, the South West Atlantic and the Antarctic. Scientia Marina 69: 91-102. 
539 Hawkins BA, Porter EE \& Diniz-Filho JAF. 2003. Productivity and history as predictors of

540 the latitudinal diversity gradient of terrestrial birds. Ecology 84: 1608-1623.

541 Herm D 1969. Marines Pliozän und Pleistozän in Nord und Mittel-Chile unter besonderer

542 Berücksichtigung der Entwicklung der Mollusken-Faunen. Zitteliana 2: 1-159.

543 Hernández CE, RA Moreno \& N Rozbaczylo. 2005. Biogeographical patterns and Rapoport’s rule in southeastern Pacific benthic polychaetes of the Chilean coast. Ecography 28: 363373.

Hillebrand H. 2004a. On the generality of the latitudinal diversity gradient. The American Naturalist 163: 192-211.

Hillebrand H. 2004b. Strength, slope and variability of marine latitudinal gradients. Marine Ecology Progress Series 273: 251-268.

Ibanez-Erquiaga B, Pacheco AS, Rivadeneira MM \& Tejada CL. 2018. Biogeographical zonation of rocky intertidal communities along the coast of Peru (3.5-13.5 $\mathrm{S}$ Southeast Pacific). PLoS ONE 13: e0208244.

Jablonski D, CL Belanger, SK Berke, S Huang, AZ Krug, K Roy, A Tomasovych \& JW Valentine. 2013. Out of the tropics, but how? Fossils, bridge species, and thermal ranges in the dynamics of the marine latitudinal diversity gradient. Proceedings of the National SP \& Webb CO. 2010. Picante: R tools for integrating phylogenies and ecology. Bioinformatics 26: 1463-1464.

Kiel S \& SN Nielsen. 2010. Quaternary origin of the inverse latitudinal diversity gradient among southern Chilean mollusks. Geology 38: 955-958. 
562 Kindlmann P, Schödelbauerová I \& Dixon AFG. 2007. Inverse latitudinal gradients in species

563

564

565

566

567

568

569

570

571

572

573

574

575

576

577

578

579

580

581

582

diversity. In: Storch D, P Marquet \& JH Brown (eds). Scaling biodiversity, pp 246-257. Cambridge University Press, Cambridge.

Kinlock NL, Prowant L, Herstoff EM, Foley CM, Akin-Fajiye M, Bender N, Umarani M, Ryu HY, Şen B \& Gurevitch J. 2018. Explaining global variation in the latitudinal diversity gradient: Meta-analysis confirms known patterns and uncovers new ones. Global Ecology and Biogeography 27: 125-141.

Kreft H \& Jetz W. 2007. Global patterns and determinants of vascular plant diversity. Proceedings of the National Academy of Sciences of the United States of America 104: 5925-5930.

Lancellotti DA \& JA Vásquez. 2000. Zoogeografía de macroinvertebrados bentónicos de la costa de Chile: contribución para la conservación marina. Revista Chilena de Historia Natural 73: 99-129.

Lancellotti DA \& Vásquez JA. 1999. Biogeographical patterns of benthic macroinvertebrates in the Southeastern Pacific litoral. Journal of Biogeography 28: 1001-1006.

Lee MR \& M Riveros. 2012. Latitudinal trends in the species richness of free-living marine nematode assemblages from exposed sandy beaches along the coast of Chile $\left(18-42^{\circ} \mathrm{S}\right)$. Marine Ecology 33: 317-325.

Liaw A \& Wiener M. 2002. Classification and regression by randomForest. Rnews 2: 18-22.

Menegotto A \& Rangel TF. 2018. Mapping knowledge gaps in marine diversity reveals a latitudinal gradient of missing species richness. Nature Communications 9: 4713.

Peer) reviewing PDF | (2020:05:48774:3:0:NEW 24 Jul 2021) 
583 Menegotto A, Kurtz MN \& Lana PdC. 2019. Benthic habitats do show a significant latitudinal

584 diversity gradient: A comment on Kinlock et al. (2018). Global Ecology and

$585 \quad$ Biogeography 28: 1712-1717.

586 Mittelbach GG, DW Schemske, HV Cornell, AP Allen, JM Brown, MB Bush, SP Harrison, AH Hurlbert, N Knowlton, HA Lessios, CM McCain, AR McCune, LA McDade, MA McPeek, TJ Near, TD Price, RE Ricklefs, K Roy, DF Sax, D Schluter, JM Sobel

\& M Turelli. 2007. Evolution and the latitudinal diversity gradient: speciation, extinction and biogeography. Ecology Letters 10: 315-331.

Montiel A, Gerdes D, Hilbig B \& Arntz WE. 2005. Polychaete assemblages on the Magellan and Weddell Sea shelves: comparative ecological evaluation. Marine Ecology Progress Series 297: 189-202. Biogeography 33: 750-759.

Moyano H. 1991. Bryozoa marinos chilenos. VIII: Una síntesis zoogeográfica con consideraciones sistemáticas y la descripción de diez especies y dos géneros nuevos.

Naimi B, Hamm NA, Groen TA, Skidmore AK \& Toxopeus AG. 2014. Where is positional 601 uncertainty a problem for species distribution modelling? Ecography 37: 191-203. Ojeda FP \& Ibáñez CM. 2020. Latitudinal distribution of polyplacophorans along the South-eastern Pacific coast: unravelling biases in geographical diversity patterns. Marine Biodiversity 50: 1-12. 
606

607

608

609

610

611

612

613

614

615

616

617

OBIS. 2021. Ocean Biodiversity Information System. Intergovernmental Oceanographic Commission of UNESCO. www.obis.org.

Ojeda FP, Labra FA \& Muñoz AA. 2000. Biogeographic patterns of Chilean littoral fishes. Revista Chilena de Historia Natural 73: 625-641.

Oksanen J, Blanchet FG, Friendly M, Kindt R, Legendre P, McGlinn D, Minchin PR, O'Hara RB, Simpson GL, Solymos P, Stevens MHH, Szoecs E \& Wagner H. 2019. Vegan: Community Ecology Package. R package version 2.5-5. http://CRAN.Rproject.org/package= $=$ vegan .

Pamungkas J, Glasby CJ \& Costello MJ. 2021. Biogeography of polychaete worms (Annelida) of the world. Marine Ecology Progress Series 657: 147-159.

Paradis E, Claude J \& Strimmer K. 2004. APE: analyses of phylogenetics and evolution in R language. Bioinformatics 20: 289-290.

Pianka ER. 1966. Latitudinal gradients in species diversity: A review of concepts. The American Naturalist 100: 33-46.

Platnick NI. 1991. Patterns of biodiversity: tropical vs temperate. Journal of Natural History 25 : 1083-1088.

\section{Pontarp M, Bunnefeld L, Cabral JS, Etienne RS, Fritz SA, Gillespie R, Graham CH,} Hagen O, Hartig F, Huang S, Jansson R, Maliet O, Münkemüller T, Pellissier L, Rangel TF, Storch D, Wiegand T \& Hurlbert AH. 2019. The latitudinal diversity gradient: novel understanding through mechanistic eco-evolutionary models. Trends in Ecology \& Evolution 34: 211-223.

Ricklefs RE. 1987. Community diversity: relative roles of local and regional processes. Science 235: $167-171$. 
629 Rivadeneira MM \& Marquet PA. 2007. Selective extinction of late Neogene bivalves on the

630

631

632

633

634

635

636

637

638

639

640

641

642

643

644

645

646

647

648

649

temperate Pacific coast of South America. Paleobiology 33: 455-468.

Rivadeneira MM \& Nielsen SN. 2017. Diversification dynamics, species sorting, and changes in the functional diversity of marine benthic gastropods during the Pliocene-Quaternary at temperate western South America. PloS One 12: e0187140.

Rivadeneira MM, Fernández M \& Navarrete SA. 2002. Latitudinal trends of species diversity in rocky intertidal herbivore assemblages: spatial scale and the relationship between local and regional species richness. Marine Ecology Progress Series 245: 123-131.

Rivadeneira MM, Thiel M, González ER \& Haye PA. 2011. An inverse latitudinal gradient of diversity of peracarid crustaceans along the Pacific Coast of South America: out of the deep south. Global Ecology and Biogeography 20: 437-448.

Rivadeneira MM \& Poore GCB. 2020. Latitudinal gradient of diversity of marine crustaceans: towards a synthesis. In: GCB Poore \& Thiel M (eds). The natural history of the Crustacea, Volume 8: evolution and biogeography of the Crustacea, pp: 389-413. Oxford University Press, New York.

Rohde K. 1992. Latitudinal gradients in species diversity: The search for the primary cause. Oikos 65: 514-527.

Rosenzweig ML. 1995. Species diversity in space and time. 436 pp. Cambridge University Press, Cambridge.

Robertson DR \& Cramer KL. 2009. Shore fishes and biogeographic subdivisions of the Tropical Eastern Pacific. Marine Ecology Progress Series 380: 1-17.

Peer] reviewing PDF | (2020:05:48774:3:0:NEW 24 Jul 2021) 
650 Roy K, Jablonski D, Valentine JW \& Rosenberg G. 1998. Marine latitudinal diversity

651

652

653

654

655

656

657

658

659

660

661

662

663

664

665

666

667

668

669

670

671

672 gradients: Tests of causal hypotheses. Proceedings of the National Academy of Sciences of the United States of America 95: 3699-3702.

Sanders HL. 1968. Marine benthic diversity: a comparative study. The American Naturalist 102: $243-282$.

Santelices B \& PA Marquet. 1998. Seaweeds, latitudinal diversity patterns, and Rapoport's rule. Diversity and Distributions 4: 71-75.

Santelices B, JJ Bolton \& I Meneses. 2009. Marine algal communities. In: Whitman JD \& K Roy (eds). Marine macroecology, pp: 153-192. University of Chicago Press, Chicago.

Santelices B. 1982. Caracterización fitogeográfica de la costa temperada del Pacífico de Sudamérica. Verificación de hipótesis y consecuencias ecológicas. Archivos de Biología y Medicina Experimentales 15: 513-524.

Shaffer G, Hormazabal S, Pizarro O \& Salinas S. 1999. Seasonal and interannual variability of currents and temperature off central Chile. Journal of Geophysical Research: Oceans 104: 29951-29961.

Soul, LC \& Friedman, M. 2015. Taxonomy and phylogeny can yield comparable results in comparative paleontological analyses. Systematic Biology 64: 608-620.

Spalding MD, Fox HE, Allen GR, Davidson N, Ferdaña ZA, Finlayson M, Halpern BS, Jorge MA, Lombana A, Lourie SA, Martin KD, McManus E, Molnar J, Recchia CA \& Robertson J. 2007. Marine Ecoregions of the World: A Bioregionalization of Coastal and Shelf Areas. BioScience 57: 573-583.

Srivastava DS. 1999. Using local-regional richness plots to test for species saturation: pitfalls and potentials. Journal of Animal Ecology 68: 1-6. 
673 Strobl C, Boulesteix AL, Kneib T, Augustin T \& Zeileis A. 2008. Conditional variable

674 importance for random forests. BMC Bioinformatics 9: 307.

675 Stevens GC. 1989. The latitudinal gradient in geographical range: how so many species coexist 676 in the tropics. The American Naturalist 133: 240-256.

677 Strub PT, James C, Montecino V, Rutllant JA \& Blanco JL. 2019. Ocean circulation along 678 the southern Chile transition region $\left(38^{\circ}-46^{\circ} \mathrm{S}\right)$ : Mean, seasonal and interannual variability, with a focus on 2014-2016. Progress in Oceanography 172: 159-198.

Tittensor DP, Mora C, W Jetz, HK Lotze, D Ricard, E Vanden-Berghe \& B Worm. 2010.

681 Global patterns and predictors of marine biodiversity across taxa. Nature 466: 1098-1101.

Tolimieri N \& Anderson MJ. 2010. Taxonomic distinctness of demersal fishes of the California current: moving beyond simple measures of diversity for marine ecosystem684 based management. PloS One 5: e10653.

Tomašových, A, J D Kennedy, T J Betzner, N B Kuehnle, S Edie, S Kim, K Supriya, A E 686 White, C Rahbek, \& Huang S. 2016. Unifying latitudinal gradients in range size and richness across marine and terrestrial systems. Proceedings of the Royal Society B: Biological Sciences 283: 20153027.

Tucker CM, Cadotte MW, Carvalho SB, Davies TJ, Ferrier S, Fritz SA, Grenyer R, Helmus MR, Jin LS, Mooers AO \& Pavoine S. 2017. A guide to phylogenetic metrics

691 for conservation, community ecology and macroecology. Biological Reviews 92: 698-

692 715.

693

Valdovinos C, Navarrete SA \& Marquet PA. 2003. Mollusk species diversity in the 694 695 Southeastern Pacific: why are there more species towards the pole? Ecography 26: 139144. 
696 Valentine JW \& Jablonski D. 2015. A twofold role for global energy gradients in marine

697 biodiversity trends. Journal of Biogeography 42: 997-1005.

698 Vegas-Velez M. 1980. Algunas consideraciones biogeográficas sobre el Pacífico sudoriental.

699 Boletim do Instituto Oceanográfico 29: 371-373.

700 Villafaña JA \& Rivadeneira MM. 2014. Rise and fall in diversity of Neogene marine

701 vertebrates on the temperate Pacific coast of South America. Paleobiology 40: 659-674.

702

703

704

705

706

707

708

709

710

711

712

713

714

715

716

717

718

Warwick RM \& Clarke KR. 1998. Taxonomic distinctness and environmental assessment. Journal of Applied Ecology 35: 532-543.

Weir JT \& Schluter D. 2007. The latitudinal gradient in recent speciation and extinction rates of birds and mammals. Science 315: 1574-1576.

Wiens JJ \& Donoghue MJ. 2004. Historical biogeography, ecology and species richness. Trends in Ecology \& Evolution 19: 639-644.

Wiens JJ \& Graham CH. 2005. Niche conservatism: integrating evolution, ecology, and conservation biology. Annual Review of Ecology, Evolution and Systematics 36: 519539.

Willig MR, Kaufman DM \& Stevens RD. 2003. Latitudinal gradients of biodiversity: pattern, process, scale, and synthesis. Annual Review of Ecology, Evolution and Systematics 34: 273-309.

Winter M, Devictor V \& Schweiger O. 2013. Phylogenetic diversity and nature conservation: where are we?. Trends in Ecology \& Evolution 28: 199-204.

Woodd-Walker RS, Ward P \& Clarke A. 2002. Large-scale patterns in diversity and community structure of surface water copepods from the Atlantic Ocean. Marine Ecology Progress Series 236: 189-203. 
719 Woolley SNC, Tittensor DP, Dunstan PK, Guillera-Arroita G, Lahoz-Monfort JJ, Wintle

720 BA, Worm B \& O'Hara TD. 2016. Deep-sea diversity patterns are shaped by energy

$721 \quad$ availability. Nature 533: 393-396.

722 Worm B \& Tittensor DP. 2018. A Theory of Global Biodiversity. Monographs in Population 723 Biology 60. Princeton University Press. 214 pp.

724 WoRMS Editorial Board .2021. World Register of Marine Species. Available from https://www.marinespecies.org at VLIZ. Accessed 2020-08-24. doi:10.14284/170

Wright MN \& Ziegler A. 2017. ranger: A Fast Implementation of Random Forests for High Dimensional Data in C++ and R. Journal of Statistical Software 77(1):1-17.

Wu J, Chen H \& Zhang Y. 2016. Latitudinal variation in nematode diversity and ecological roles along the Chinese coast. Ecology and Evolution 6: 8018-8027.

730 
Figure 1

Figure 1. Latitudinal diversity gradient of benthic polychaetes along the SEP.

A) Regional (using a range-through approach) and B) local scale (rarefied species richness using $E s=20$ individuals per site).

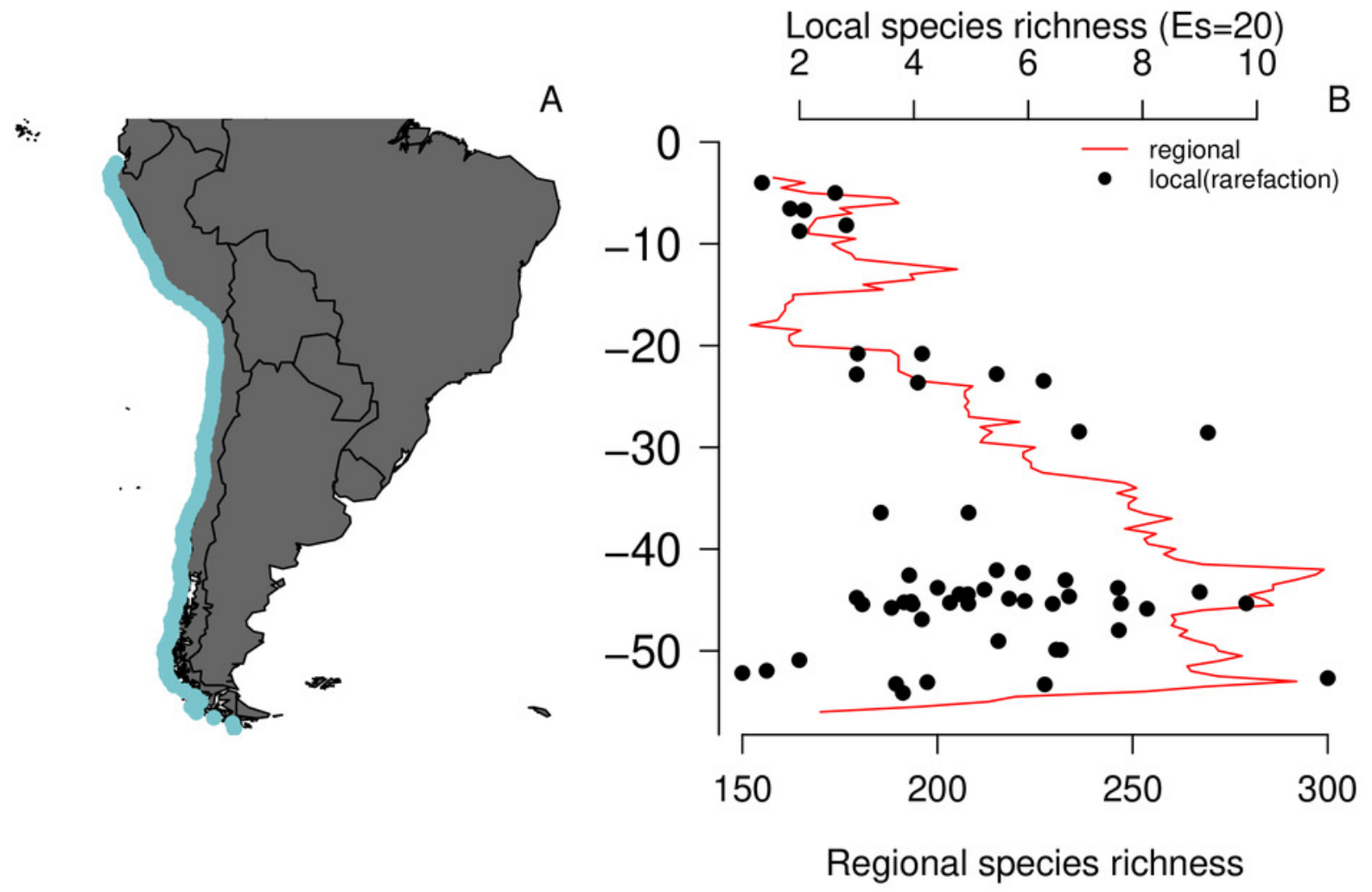


Figure 2

Figure 2. Diagnostic plots for the random forest model.

A) observed versus predicted species richness, B) latitudinal distribution of standardized residuals, and C) spatial autocorrelogram of the residuals (gray area shows the 95\% confidence intervals of a null model).

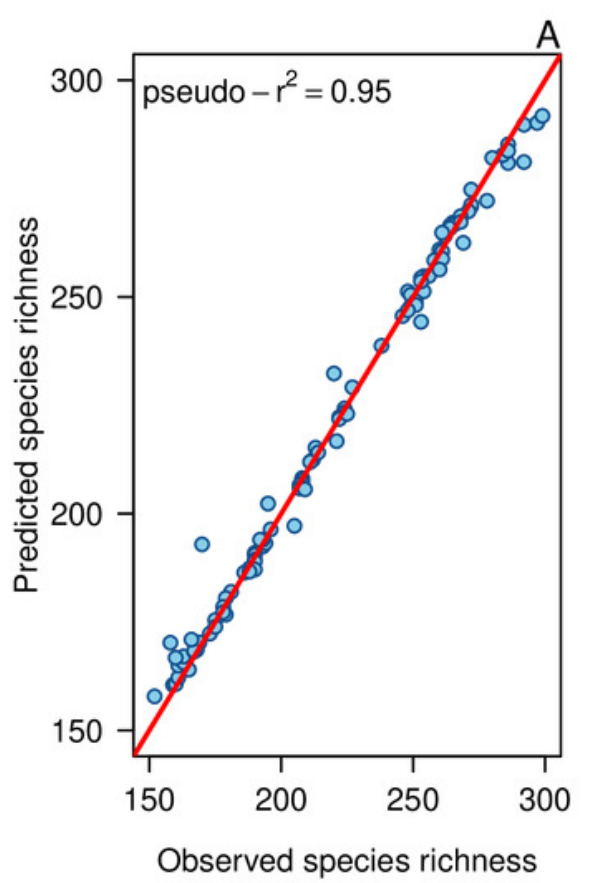

Observed species richness
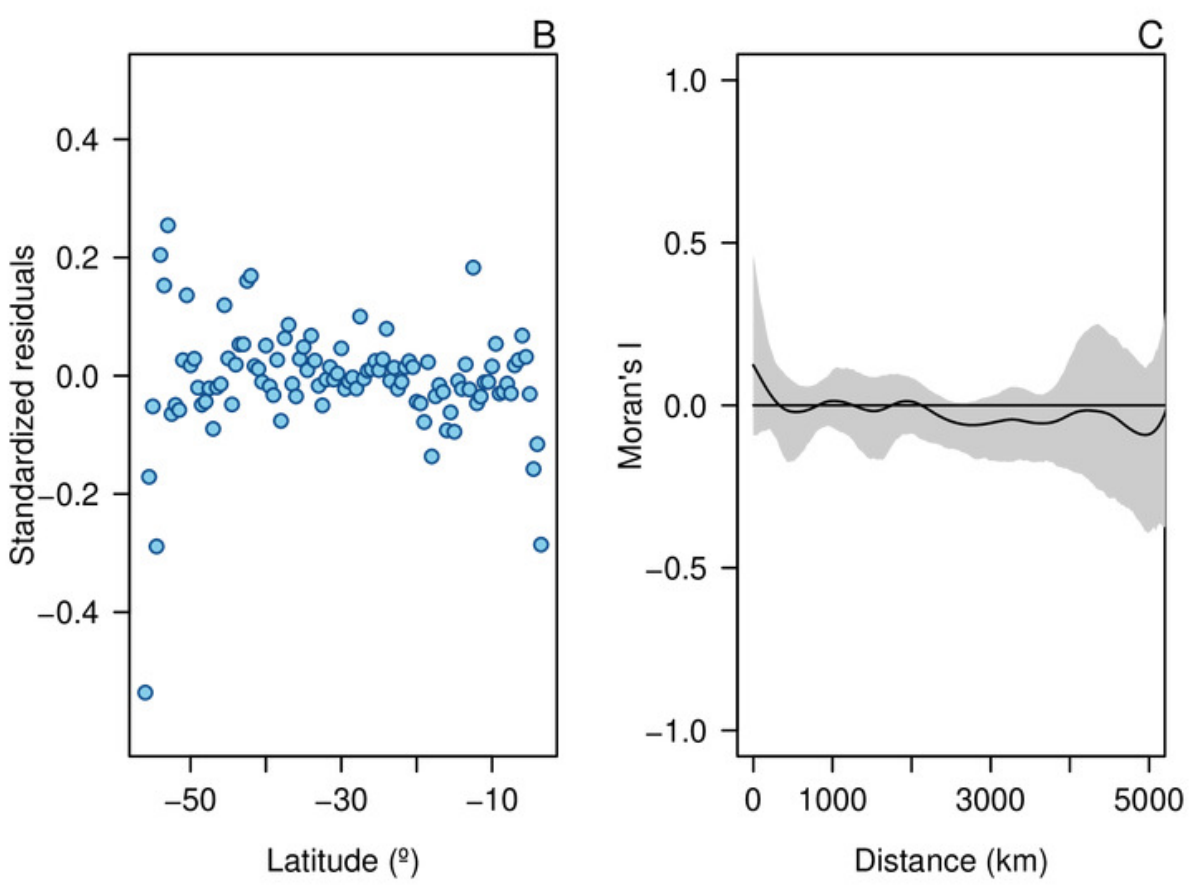
Figure 3

Figure 3. Environmental predictors of the latitudinal diversity gradient of benthic polychaetes along the SEP.

A) observed and predicted species richness by a random forest model, B) latitudinal variation of SST and SST range, and C) latitudinal variation of salinity and median latitudinal range of species. 

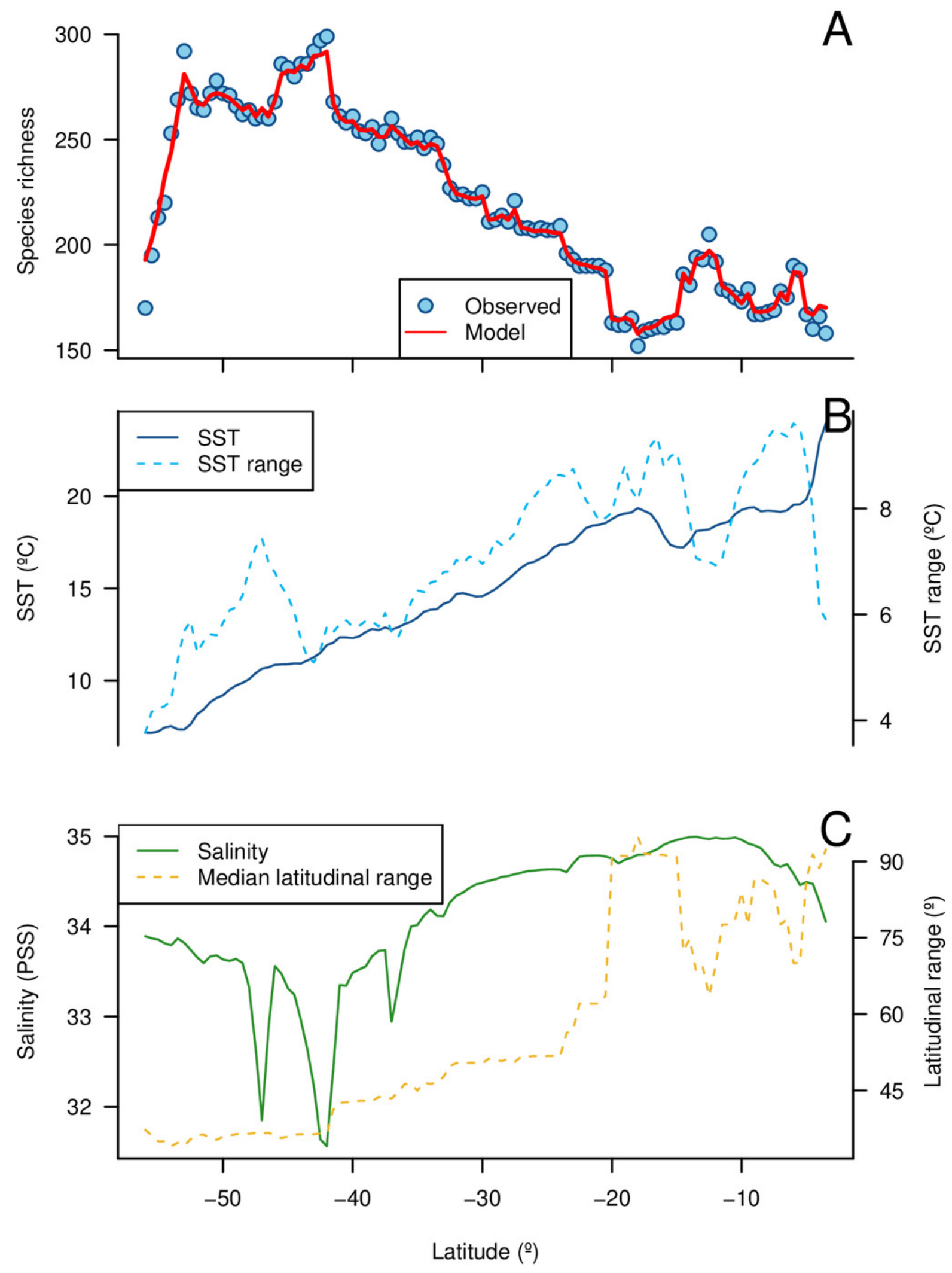
Figure 4

Figure 4. Partial dependence plot showing the relationship between predicted species richness of benthic polychaetes and the selected explanatory variables.

A) SST, B) SST range, C) salinity, and D) median latitudinal range.
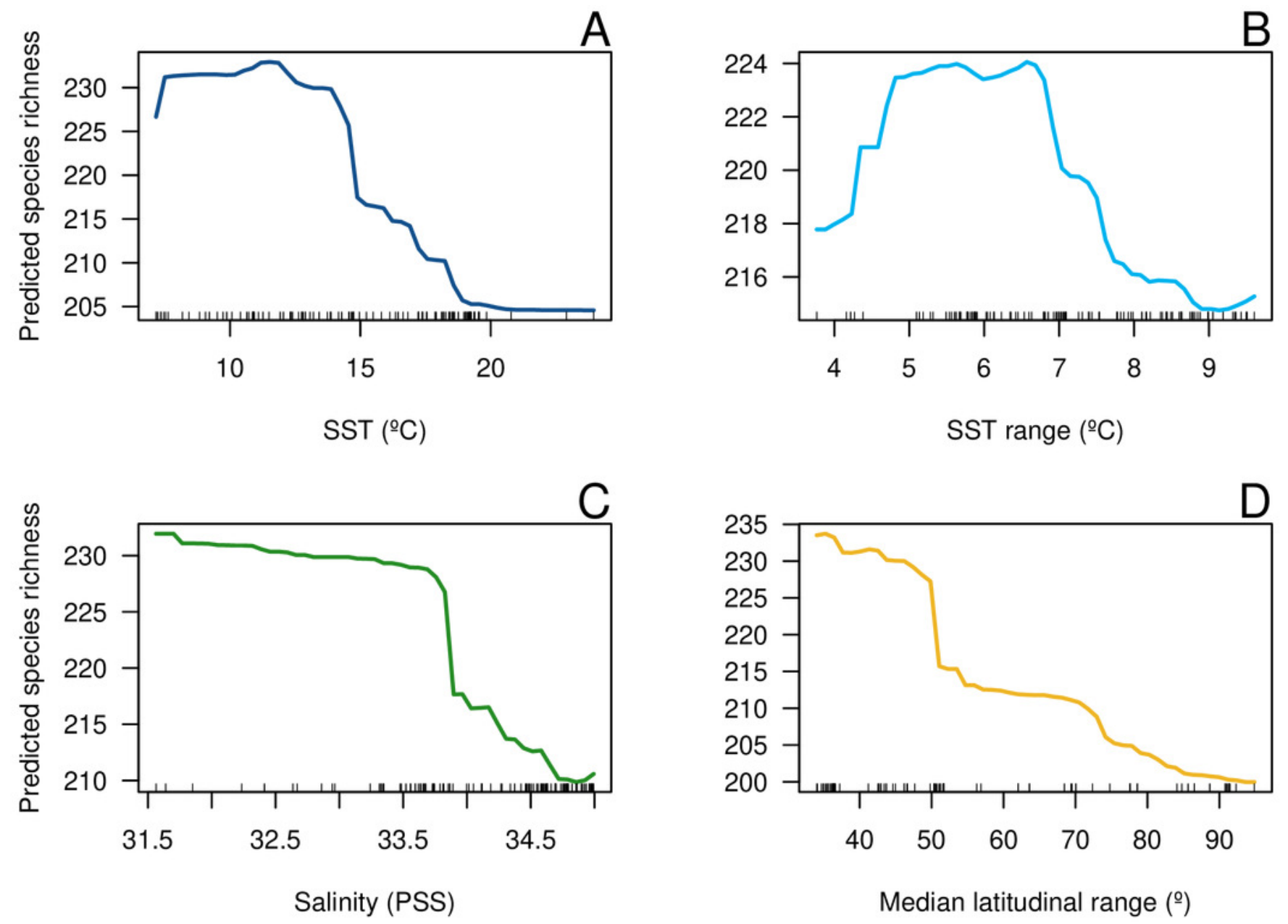
Figure 5

Figure 5. Latitudinal gradient of phylogenetic diversity of benthic polychaetes along SEP.
A) Faith's phylogenetic diversity (PDSES), B) mean pairwise distance (MDPSES), and C) variance in pairwise distance (VPD). 

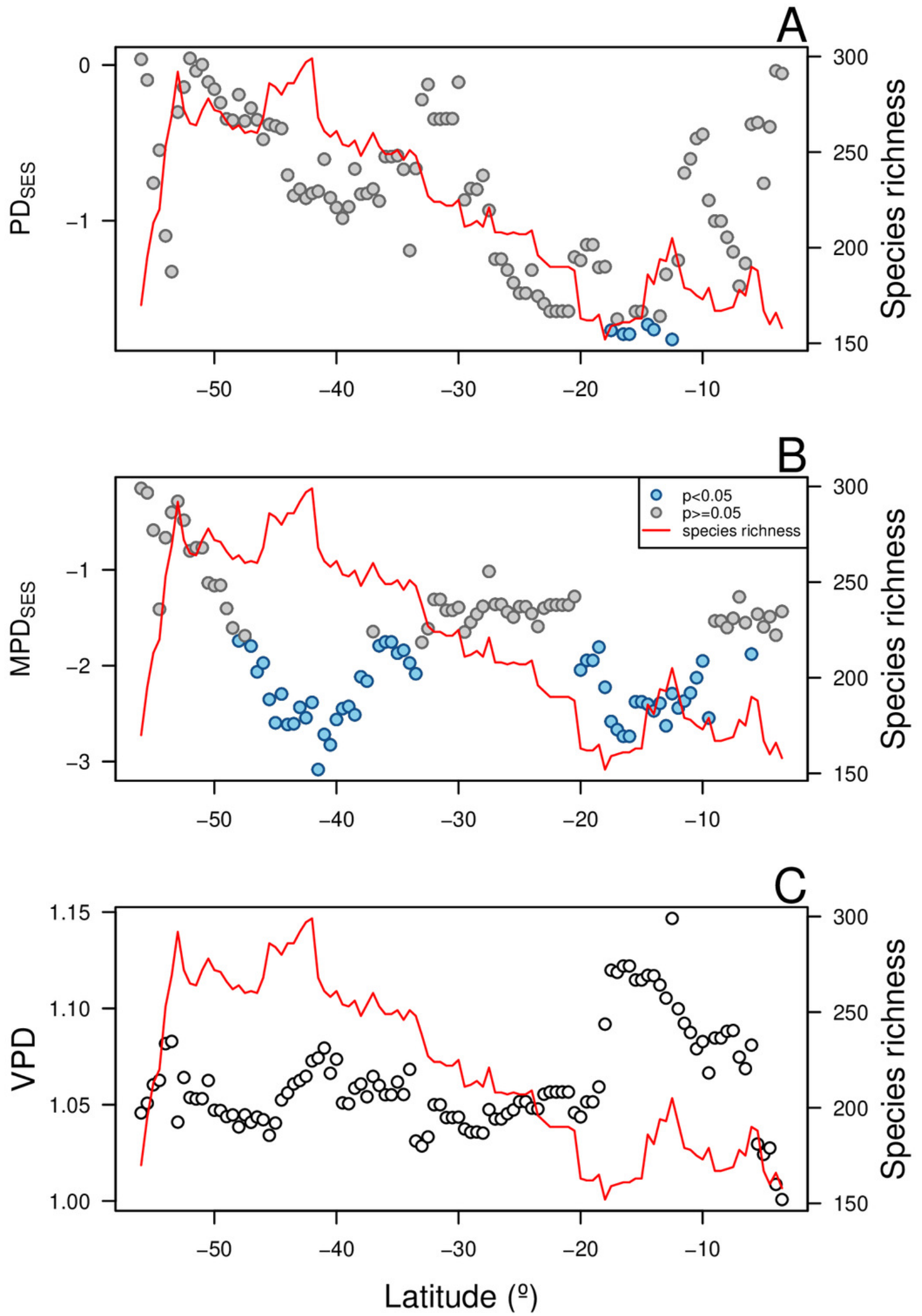


\section{Table $\mathbf{1}$ (on next page)}

Table 1. Summary of the main predictions from classic hypotheses to explain LDG. 


\begin{tabular}{|c|c|c|c|c|c|c|c|c|}
\hline $\begin{array}{c}\text { Hypothesis } \\
\text { categories }\end{array}$ & $\begin{array}{c}\text { Specific } \\
\text { hypothesis }\end{array}$ & SST & Salinity & SST range & $\begin{array}{c}\text { Median } \\
\text { lat. Range }\end{array}$ & $\begin{array}{c}\text { Salinity } \\
\text { range }\end{array}$ & Shelf area & $\begin{array}{c}\text { Primary } \\
\text { productivity }\end{array}$ \\
\hline \multirow[t]{3}{*}{ Ecological limits } & $\begin{array}{c}\text { Seasonal } \\
\text { coexistence }\end{array}$ & & & $\begin{array}{l}\downarrow \text { range, } \\
\uparrow \text { species }\end{array}$ & & $\begin{array}{l}\downarrow \text { range, } \\
\uparrow \text { species }\end{array}$ & & \\
\hline & $\begin{array}{c}\text { Species-area } \\
\text { effect }\end{array}$ & & & & & & $\begin{array}{l}\uparrow \text { area, } \\
\uparrow \text { species }\end{array}$ & \\
\hline & $\begin{array}{c}\text { Energy- } \\
\text { dependency }\end{array}$ & & & & & & & $\begin{array}{c}\uparrow \text { PrimProd, } \\
\uparrow \text { species }\end{array}$ \\
\hline \multirow[t]{2}{*}{$\begin{array}{c}\text { Diversification } \\
\text { dynamics }\end{array}$} & $\begin{array}{c}\text { Long term climate } \\
\text { stability }\end{array}$ & & & & $\begin{array}{l}\downarrow \text { range, } \\
\uparrow \text { species }\end{array}$ & & & \\
\hline & $\begin{array}{c}\text { Temperature- } \\
\text { dependent } \\
\text { speciation }\end{array}$ & $\begin{array}{c}\uparrow \mathrm{SST}, \\
\uparrow \text { species }\end{array}$ & & & & & & \\
\hline $\begin{array}{l}\text { Time for species } \\
\text { accumulation }\end{array}$ & $\begin{array}{c}\text { Niche } \\
\text { conservatism }\end{array}$ & & \multicolumn{4}{|c|}{$=$ conditions of origination, $\uparrow$ species } & & \\
\hline
\end{tabular}




\section{Table 2 (on next page)}

Table 2. Environmental predictors of the LDG of benthic polychaetes along the SEP.

These predictors are proxies of different hypotheses grouped into three categories (sensu Pontarp et al. 2019). Also shown are their level of collinearity (variance inflation factor, VIF), variable importance according a conditional random forest analysis and their phylogenetic signal (Blomberg's K). 
Conditional random forest Phylogenetic signal

\begin{tabular}{lccccc}
\hline Proxy & VIF & Conditional importance & p-value & $\mathrm{K}$ & $\mathrm{p}$-value \\
\hline Median lat. range & 6.26 & $\mathbf{8 3 1 . 5 2 5}$ & $\mathbf{0 . 0 0 0 1}$ & $\mathbf{0 . 3 0 7}$ & $\mathbf{0 . 0 0 3}$ \\
SST & 9.33 & $\mathbf{7 3 2 . 8 1 4}$ & $\mathbf{0 . 0 0 0 1}$ & $\mathbf{0 . 3 3 2}$ & $\mathbf{0 . 0 0 1}$ \\
Salinity & 3.71 & $\mathbf{5 4 1 . 3 4 8}$ & $\mathbf{0 . 0 0 0 1}$ & 0.274 & 0.725 \\
SST range & 3.18 & $\mathbf{2 1 7 . 9 7 8}$ & $\mathbf{0 . 0 2 2 7}$ & 0.290 & 0.162 \\
Primary productivity & 2.81 & 149.033 & 0.0805 & $\mathbf{0 . 3 0 1}$ & $\mathbf{0 . 0 0 7}$ \\
Salinity range & 1.88 & 129.715 & 0.0822 & 0.286 & 0.215 \\
Shelf area & 1.64 & 58.671 & 0.2966 & - & - \\
\hline
\end{tabular}

